\title{
Multidisciplinary Team-Based Model for Faculty Supports in Online Learning
}

\author{
Bev King, Christina Dinsmore, Antoinette Thornton, \\ Wanda Beyer, Keren Akiva, CJ Dalton
}

This study examined the experiences of three new online instructors supported by a multidisciplinary, team-based model of course development and how their experiences may transform their knowledge of teaching and learning. In-depth, individual interviews with instructors during the course development process provided insights into participants' perspectives. Analysis reveals faculty reflected positively on the overall development process and that they intend to incorporate new understandings in future course design, suggesting that the model provides a solid foundation for online course development and faculty support. Based on a cross-case analysis using Cranton's (2002) adaptations to transformative learning theory, findings indicated the importance of critical reflection and discourse during the course development process. Lastly, the need for development teams to acknowledge timemanagement concerns and to consider instructors as novice learners is recognized as an essential requirement to online course development.

La présente étude se penche sur l'expérience de trois nouveaux instructeurs en ligne utilisant un modèle d'élaboration de cours multidisciplinaire fondé sur le travail d'équipe. Nous nous demandons comment cette expérience est susceptible de transformer leur connaissance de l'enseignement et de l'apprentissage. Des entrevues individuelles approfondies avec les instructeurs pendant l'élaboration des cours nous ont permis d'observer le point de vue des participants. Selon notre analyse, les enseignants ont formulé des réflexions positives au sujet $d u$ processus d'elaboration dans son ensemble. Ils ont dit vouloir incorporer leurs nouvelles connaissances dans la conception de leurs cours à l'avenir, ce qui suggère que le modèle constitue une assise solide pour l'élaboration de cours en ligne etpour le soutien des enseignants. Fondés sur une analyse transversale faisant usage des adaptations de Cranton (2002) aux théories de l'apprentissage transformationnel, nos résultats mettent en relief l'importance de la réflexion critique et du discours dans le processus d'élaboration des cours. Enfin, nous prenons acte du fait que l'équipe d'elaboration des cours doit prendre en compte les préoccupations en matière de gestion du temps et doit considérer les instructeurs comme des apprenants débutants. Ce sont là des exigences essentielles pour l'élaboration de cours en ligne. 


\section{Multidisciplinary Team-Based Model for Faculty Supports in}

\section{Online Learning}

$\mathrm{W}$

hile online learning was previously explored only by "venturesome instructors" or "early adopters" (Wilson and Stacey, 2003, p. 543), it is now widely accepted in mainstream education (Donovan et al., 2018). With the recent increase in online course offerings, academics are now challenged to be experts in both on-campus and online instruction. One of the main barriers to teaching online is a lack of adequate training and support to transition from teaching in the face-to-face environment to online learning (e.g., Bower, 2001; Covington, Petherbridge, \& Warren, 2005; Donovan et al., 2018; Kebritchi, Lipschuetz, \& Santiague, 2017). These supports help to overcome attitudinal barriers toward online teaching, and provide the skills and knowledge required to enable stronger pedagogical and technological course design. Empowering faculty to make the leap to online design and delivery is a complex endeavour, requiring focused interventions that mitigate instructors' concerns and enable a shift from faculty teaching to student learning (Allen, 2017; Barker, 2003; Brown, 2016; Giovanni \& Tesone, 2004; Kraglund-Gauthier, Chareka, Orr, \& Foran, 2010; Riches \& Benson, 2011).

The primary purpose of this qualitative study is to explore how three new online instructors experience a multidisciplinary team-based faculty support model, and how these experiences may be described as transformative with respect to their pedagogical knowledge of teaching and learning. A secondary goal is to inform the enhancement, formalization, and documentation of a team-based model of faculty support for online course development. Research questions include the following: What are the experiences of instructors developing online courses with a team-based faculty support model? How might participants' experiences be understood using
Transformative Learning Theory or related models (Cranton, 2002; Mezirow, 1996)? What recommendations can be made for enhancing a teambased approach to faculty supports in online course design?

The Multidisciplinary Team Approach to Online Course Development

Quality online course development is a "complex endeavour ... requiring highly organized, concerted effort from many players" (Caplan, 2004, p. 186). The multidisciplinary team approach used in this study provided course design and online pedagogy expertise from many players, such as faculty members (as subject matter experts), instructional designers, and learning management systems specialists. The design and development process includes four distinct and iterative stages, tailored to the specific needs of the course and faculty member:

1. Planning and initial development: A plan and timeline for each stage of development are determined. The syllabus is created by the instructor and the instructional designer and assessed by an external reviewer using the Quality Matters framework (Quality Matters framework is a set of quality expectations for online and blended courses in higher education) This stage typically takes about a month.

2. Beta-testing: A complete module of material and activities is developed and is beta-tested online. This stage takes approximately a month.

3. Course development: Using the feedback from beta-testing, the team designs, develops, reviews, reflects, revises, and finalizes course materials and activities for the remaining modules. This stage is extensive and takes a minimum of three to four months.

4. Quality assurance review: The development process culminates in all members of the design team (plus additional stakeholders) reviewing and revising the course, using 
criteria from Quality Matters. Typically, this stage requires a month.

This design process is complex, as the instructional designer and the team attempt to achieve several goals at once, from orienting the faculty member to the process of course design and development to providing pedagogical and technical training to the faculty member.

\section{Methodology}

This research study used a case study methodology to capture the in-depth experiences and multiple perspectives of three instructors (Stake, 2000). With clearance from the General Research Ethics Board at the university, the study generated three cases of faculty members through purposive sampling. These faculty members, who were new to online course development and instruction, were scheduled to participate in the course design process during the nine-month period allocated to data collection. A research assistant was responsible for data collection to reduce bias and mitigate the possibility that that faculty members may feel judged on their knowledge of pedagogy (Kreber, 2004). Each participant's course development project began and concluded with a 45-minute interview. Between these start and end points, participants met regularly with their course development teams (the number of meetings for each participant varied from 10 to 14, depending on the project plan). Following each individual course development meeting, the participant was interviewed, and a script was used to ensure consistency across interviews and to elicit context and deeper understanding of their experience and pedagogical knowledge, attitudes, and behaviours. Interview data were analyzed both inductively and deductively to capture emergent themes. Interview data were analyzed using an emic approach. A crosscase, deductive analysis was also undertaken using themes from transformative learning theory with
Cranton's (2002) seven facets for transformative learning as a framework.

\section{Case Studies}

As mentioned, an emic (or bottom up) approach was initially used to analyze the data. Through this approach, we were able to identify themes in the data and (re)construct a coherent narrative for each of the cases. As such, the case study descriptions in this section represent the participants' experiences told from their own perspectives, including recommendations for faculty support.

Two major themes emerged during inductive analysis of the case studies: perspectives on pedagogy and online learning and experiences with the course development process. Within the latter theme, additional subthemes emerged:

1. The team as a resource;

2. Sharing control and trusting the team;

3. Time pressures; and

4. Recommendations for faculty support.

Each narrative is introduced with the participant's background as context and arranged in order of these themes.

\section{Case One: Andrew}

Andrew was a long-time university adjunct professor with an infectious enthusiasm for teaching and connecting with students. He had previously used learning management systems to augment classroom instruction but had not developed or delivered an online course before this study. Andrew thought he couldn't "possibly duplicate that classroom experience." Andrew believed his role was "about teaching the learner to reexamine and change their capacity... to analyze... to develop a lens." 


\section{Pedagogy and online learning}

In designing a course with the development team, Andrew reported that he was "starting from the learning outcomes," and admitted that "designing it with that in mind and working through the assessments is a different approach," which was a "big hurdle" for me." Previously, "I would design my lecture with the objectives, but I wouldn't have done that at the beginning.... In designing the syllabus..., I didn't think a lot about mapping it back." He came to recognize that there was "some value in just thinking about the end product no matter what the content is.... I'm definitely excited."

\section{Experiences with the Course Development} Process

The Team as a Resource: Following his third development meeting, Andrew reported that "they [the team] have all this rich set of things other instructors have tried out." In subsequent meetings, Andrew said, "I'm getting more information about what some of the options are or opportunities are that I didn't have before." As an example, Andrew explained that he presented the team with classroom teaching activities that he wanted to try online and "the team has a solution about how they can actually make it happen." Overall, Andrew reported having "a richer understanding of the opportunities for multimedia" and of "being much more intentional" about the learning objectives and assessments.

Sharing Control and Trusting the Team: After an early team meeting, Andrew revealed that designing the course had been "a challenge because I don't control all the pieces." By his eighth team meeting, Andrew stated, "I have a lot of trust in the process... the core team, we've been working together for a while.... There's a lot of people involved, there's energy... just a lot of stuff going on, people know their roles, and it's really cool to watch it come together, because normally, it's all me."
Time Pressures: Andrew admitted that mid-way through the development process, he "felt overwhelmed" and wondered "is this all going to get done on time?"' He "felt defeated, mostly, because I just couldn't in the moment imagine how I could resolve what they needed to get done.... It's challenging because the pressure is on, everyone is trying to get things done." Ultimately, Andrew said that developing his course "has its challenges, but I would do it again."

\section{Recommendations for Supporting Faculty}

Members: Andrew would have preferred in the first meetings to have the team "describe the process in its entirety. What's it going to look like, what are some of the challenges?" In addition, "I would advise more time at the beginning... in orientation... for more clarity of how the team is sharing the work." Andrew suggested that it would be helpful to have a "checklist" or a way to "conceptualize what the design process is... a schematic way of displaying it in a fairly precise manner... a flowchart or a little video that you... can go back and check." As a final point, Andrew suggested that "having a faculty member... in some way contribute to that learning curve... [by] being a resource... or having a mentorship opportunity, would be really great" in enhancing the development experience in the future.

\section{Case Two: Beth}

Beth was a second-year tenure-track faculty member. Although new to teaching and to online development, she had been a graduate teaching assistant with the Centre for Teaching and Education at her alma mater. Beth remarked that a teaching workshop she had attended for new faculty members when she started her position was mainly "focused towards on-campus delivery" of courses. After delivering an on-campus course for a certificate program the previous year, Beth was, at the time of this study, preparing the same course for a new online offering. 


\section{Pedagogy and Online Learning}

Beth communicated interest in developing pedagogically sound approaches to course design. Working with the course development team and developing her course for an online classroom triggered reflection on her teaching goals.

When discussing the development of learning activities, such as jeopardy, word puzzles, and branching activities, Beth recalled feeling that she was "heading in a whole different direction ... which isn't necessarily a bad thing." Beth reported that the activities being developed for her course were "more in-depth in terms of pedagogical theory." Previously, she "didn't have scaffolding and didn't try to align assessments with content." Thinking back to her oncampus course, Beth conceded, "I didn't incorporate any reflection pieces ... or any student interaction into the assessment," whereas now "this online course development [process] is making me think it through."

Despite these shifts in Beth's perspectives about pedagogical design, she expressed caution about certain aspects of online learning. She discussed her belief that online courses were "less friendly" compared to on-campus courses, where "you're teaching in person, it is synchronous ... so you don't have to bridge that divide." She also expressed concern about the responsiveness of online courses, saying that in traditional teaching, "if something isn't working mid-semester . . ., you can do something to change it, right?" In addition, Beth revealed that during her on-campus course she "was making all the decisions," whereas "now it is a discussion of what type of assessments are more appropriate for an online environment."

\section{Experiences with the Course Development}

\section{Process}

The Team as a Resource: Learning about team members' roles gave Beth a sense of "who I need to turn to, in terms of different tasks." She described the multidisciplinary team approach as "quite expansive in terms of covering many topics and aspects of course development."

Time Pressures: Due to other work priorities and family commitments that affected Beth's schedule, course development had to be condensed into four months. Subsequently, she said that "a lot of my anxiety for the course development is in the process of the development itself." By her sixth of ten meetings, Beth emphasized this time pressure: "What is making my course development tough right now is the time frame.... It's just the biggest issue." Being new to the online teaching environment, she said that "the assessments are just more complex." Yet, because of the time constraints, she was unable to pursue many of the suggested possibilities, such as developing more interactive content. Thus, Beth said that she was working "on the bare minimum of what needs to be done for my course to be operational.... There's definitely more to be done."

\section{Recommendations for Supporting Faculty}

Members: Beth wished she had been given a "cheat sheet" of all the online learning concepts and activities available to her, so she could have "go[ne] through it more in-depth on her own time." She wanted "something that talks about blended learning or scaffolding or active learning." Beth also noted that "having a bit more access to visual examples of the end product" would have also enabled her to come to the meetings "a little more prepared."

\section{Case Three: Grace}

Grace holds an advisory position with university administration, and admitted she "had no experience with online course design, and I had very little experience teaching at all... I just agreed to develop and teach this course and [felt] honored to do so." Being unfamiliar with both face-to-face and online course development, Grace also had minimal exposure to learning management systems. "I was a 
moldable piece of clay," Grace said. "I had no preconceived notions about how courses should be developed [and] I didn't need to be talked out of my deep expertise in traditional course development."

\section{Pedagogy and Online Learning}

In her exit interviews, Grace reported a perspective shift in the way that she thought about course design, learning outcomes, and assessments. In the past, she developed content for a lecture by asking herself, "What is it that I know, that I want [students] to know?' As opposed to 'What is it that we want them to be able to do? And therefore, what do they need to know?"' After only a few meetings with the development team, Grace remarked that she found it "helpful" to "tie the lecture content to the assessment and back to the learning outcome."

While Grace appreciated the opportunities that online teaching and learning presented, she believed that "some things are just never going to be quite the same as a traditional lecture course." Grace admitted, "I don't have a script when I teach.... I wing it." She "really feeds on the nervousness that giving a lecture to a live audience develops," so "the thing I found most difficult" about creating a podcast was "to sit in an empty room" and generate that energy on her own. Furthermore, with respect to activities and assessments, Grace felt that "online discussion forums will never compare to a really vibrant open discussion ... where you can see each other's body language."

After her sixth team meeting, Grace said, "I definitely have a broader perspective on the types of assessment tools that are available ... the stuff that can be done online. It's maybe one area that going online actually expands what you can do as opposed to restricting it.... The online environment provides some real opportunities that don't exist in the traditional lecture course."
Experiences with the Course Development Process

The Team as a Resource: Clearly enthusiastic, Grace recalled that "it was really eye opening, just the number of different ways the assessments could be done.... It is really cool." Following a later course development meeting, Grace reported that the team was "discussing evaluation context, appropriate evaluation, scalable evaluation. I was really impressed with the team.... They were all quite excited ..., and we were able to decide how the assessments could be more directly related to what we're trying to teach: resilience."

Time Pressures: Grace said that "time pressure got really heavy..., and it starts losing the fun factor.... We should have started earlier in the calendar.... I would maybe do a week of content every two weeks."

\section{Recommendations for Supporting Faculty}

Members: Grace felt that developing an online course with the team "was a bit overwhelming earlier in the process; I didn't even know what questions to ask." Grace added, "It would have been good to have known the full suite of technological tricks." She confirmed that she would have preferred a "broader discussion of the pitfalls and possibilities of going online" in an earlier meeting.

\section{Summary of Cases}

There were evident commonalities in the way participants viewed the course development model, experienced the process, and changed their perspectives throughout. In terms of the team-based model, participants referenced the team as a resource - a source of experience and expertise — and viewed this resource as critically important to their course development success. Participants reported that this process allowed them to revisit (and in some case challenge) their assumptions about teaching and learning. To varying degrees, all participants spoke to feeling overwhelmed during the initial stages of the 
development process, and to being challenged by pedagogical concepts and the application of online design principles.

\section{Cross-Case Analysis}

We recognize that although learning to design, develop, and deliver courses online may be a "catalyst for faculty to reflect on and evaluate their current teaching practices" (McQuiggan, 2012, p. 27), we cannot teach transformation (Cranton, 2002, p. 70). Thus, the multidisciplinary team aims to foster a supportive environment for faculty members to challenge their "beliefs, assumptions, and perspective" (Cranton, 2002, p. 66), and we hope to better support moments of critical learning in which faculty members reflect on and revise assumptions about teaching and learning online, and pedagogy in general.

Cranton's (2002) model acts as a guide for deductive analysis of the data in this study. While we explored other adult learning theories, such as social learning theories, as potential frameworks for this study, these theories did not capture the "deeply felt" changes that had been anecdotally reported by faculty members supported by the team-based support model and observed by instructional design teams (King, 2004, p. 168). In the following sections, we compare facets to the data that emerged from participant interviews.

\section{Activating Events}

An "activating" event, often referred to as "disorienting" (Mezirow, 1997), is one in which dialogue and fresh thinking are sparked as learners become aware of discrepancies between their viewpoints and alternative perspectives (Cranton, 2002). Activating events have also been described as "teachable moments" (Keen \& Woods, 2016).

Activating events across the cases were experienced when typical face-to-face approaches to course content and delivery required adaptation to suit the online environment. Beth noted her difficulty in adapting three-hour lectures to chunked units of learning (e.g., several 10-minute podcasts). Specifically, the need to alter both the structure of how she delivered content and the amount delivered to optimize students' cognitive processing challenged Beth's prior assumptions about her role as teacher, in which she saw herself as responsible mainly for imparting knowledge in a traditional lecture. Andrew had to find alternative ways to "connect" with his students, provide spontaneous feedback, and facilitate learning. "It's all stuff I haven't tried before and it's really cool.... It pushes me outside of my comfort zone, so I'm excited and scared." Grace compared her preferred "public speaking style" with a live audience to "speaking to an empty room" for her online course. Having never previously taught a complete course, Grace also admitted to being quite "at sea" at the beginning of the online course development process, and specifically when exposed to new and unfamiliar approaches for pedagogy.

\section{Assumptions}

In Teaching for Transformation, Cranton (2002) notes that "we expect what has happened in the past to happen again" and that "it is easier and safer to maintain habits of mind than to change" (p. 65). Andrew and Beth articulated that they believed online teaching and learning to be "less friendly, with constraints," and Grace expressed assumptions that online learning was "a bit restrictive" due to lack of "face-to-face interaction." Beth also expressed feeling perplexed about needing to "come up with assessments before content, revealing her assumption that online strategies minimized traditional oncampus assessments.

According to Cranton (2002), learners may also recognize shifting or new assumptions as transitional "moments" of actual learning. Andrew explained that his "biggest challenge" was "suspending" his assumptions about online courses and the 
"translation" of his on-campus course to the online course design. In her final interview, Grace articulated a new belief that teaching online "expands what you can do, as opposed to restricting it" and Beth stated that she would definitely include opportunities "for more student engagement activities."

\section{Critical Reflection}

Critical reflection was evident in how participants reported their learning and work processes, early assumptions, reasons for feeling discomfort, and resistance to giving up control. For example, Andrew and Grace revealed that their interest in being able "to connect with" and be responsive to students, and to have "real-life activities" in their courses came from a need to be energized by their students through invigorating lessons and to gain satisfaction and reassurance from student feedback. In her on-campus course, Beth "was making all the decisions" and choosing the assessments she "wanted to do." During the course development process, Beth struggled to use assessments "more appropriate for an online environment" but came to "understand the pedagogical reasons" behind them. Across all cases, critical reflection provided the opportunity for selfawareness, with participants examining previous assumptions to develop a meaningful learning experience for their online students.

\section{Trust}

As a quality that enables authentic communication, trust may be viewed as a necessary condition to being open to alternative ideas and thus transformation (Eisen, 2001). Cranton (2002) alludes to the role of trust in noting that it is challenge that "underlies teaching for transformation. Although challenge must be combined with safety, support, a sense of learner empowerment" (p. 66). In this study, needing "to trust the team" was articulated as important. At the same time, participants were challenged to find a balance in giving over some control while maintaining their academic identity and accountability for their teaching.

\section{Critical Discourse}

In these case studies, participants reported learning about new ways to approach course design, learning outcomes, assessments, and activities with course design teams facilitating the construction of knowledge in every aspect of the course. Andrew and Grace discussed the team's explorations of student engagement activities. Beth expressed her understanding of the pros and cons of varying design approaches as they were considered and weighed with her design team. Across all three cases, these instructors were engaged in increasingly authentic critical discourse about their own and others' roles, the opportunities and limitations for course design, and alternative approaches to creating their courses.

\section{Testing or Acting on Revisions}

When learners have opportunities to test and act on their revised assumptions or altered perspectives, they are more likely to adopt and apply a new paradigm (Cranton, 2002; Cranton \& Taylor, 2012). Although participants reported feeling stress in applying new perspectives, each acknowledged that they tested and revised their assumptions in response to newly acquired knowledge, with ongoing support from the team. Through the experience of developing her course with the team, implementing new ideas, and receiving feedback, Grace said that she had a "deeper understanding" and a "better perspective" of what online course development "looks and feels like." Likewise, the application of new perspectives and the quality assurance process brought Andrew "a richer understanding of the opportunities for multimedia," and he became "much more intentional" about the learning objectives and assessments. 


\section{Summary of Cross-Case Analysis}

It is evident through cross-case analysis that participants' experiences of online course development with a support team was an activating event that afforded multiple opportunities to reflect and to identify and revise current assumptions. Critical discourse about the opportunities and limitations presented by online learning played a pivotal role in the process. Supporting and empowering participants established trust, which allowed them to be open to alternative ways of thinking about teaching and learning. As faculty members tested and applied new perspectives during the course development process, they deepened their understanding, gained confidence and expertise, and demonstrated evidence of transformative learning.

\section{Limitations}

While the goal of the research project was to describe the experiences of faculty members undertaking a course development process, we also recognize that using a qualitative research design is not without critique (e.g., Cranton, 2013; Cranton \& Taylor, 2012; Newman, 2012). For example, Cranton (2013) argues that a case study approach with a subsequent thematic analysis will not produce new results, but more of the same. With "subjectivity and objectivity central in understanding different approaches to research" (Cranton 2013, p. 42), alternative frameworks, such as critical or positive paradigms, may be better suited to analyzing the breadth and depth of transformative learning theory in practice.

While the case study participants provided rich insights about their experiences, using this approach has further limitations. The case study of the development of three online courses limited the range of variation availability (Stake, 2010). Our participant selection was narrow due to the constraints of selecting participants that met our criteria and collecting data within a nine-month period to align with the course development cycle.
A common critique of qualitative methods is lack of reliability due to limited accommodation for personal bias to ensure "the precision in which the findings accurately reflect the data" (Noble \& Smith, 2015, p. 34). To mitigate this bias in our research, a research assistant collected the data and conducted the analysis using inductive and deductive approaches. We were cautious to ensure that the "methods undertaking and findings reported were not intrinsically linked to the researchers' philosophical position, experiences and perspectives" (Noble \& Smith, 2015, p. 34), but rather reflected the experiences described by the case study participants.

\section{Recommendations}

We recognize that although learning to design, develop, and deliver courses online may be a "catalyst for faculty to reflect on and evaluate their current teaching practices" (McQuiggan, 2012, p. 27), we cannot teach transformation (Cranton, 2002, p. 70) nor ensure that a faculty member will experience transformation. Having said that, given the relationship between the need for support and the adoption of research-based practices in online learning (Grover, Walters, and Turner, 2016), developing an online course within a multidisciplinary team-based model can provide a supportive environment for faculty to challenge their "beliefs, assumptions, and perspective" (Cranton, 2002, p. 66). Based on this study, the following recommendations are made:

1. Onboarding: At various points in the study, participants articulated feeling challenged by pedagogical concepts in online course development and overwhelmed with the many tasks and information being presented. The provision of an onboarding program with explicit use of pedagogical constructs that anchor and scaffold learning would support new faculty members' orientation to online learning and course design. To minimize cognitive overload, this 
onboarding program would be separate from the course development process.

2. Critical Self-Reflection: The modelling of critical self-reflection and establishing the practice as a group norm is a pragmatic approach to support transformative learning (Cranton, 2001, 2002). The interviews conducted for this study provided the impetus and a sounding board for faculty to reflect on, test and revise assumptions. To promote reflection and support faculty through moments of critical learning, time and space in the course development process could be intentionally allotted to allow for dialogue that supports faculty members in questioning and examining assumptions (Cranton, 2002). The development of a peermentor program may also facilitate critical discourse and enhance subsequent development experiences (Covington, Petherbridge, and Warren, 2005; Grover, Walters, and Turner, 2016).

3. Trust: Participants discussed their openness to new pedagogical approaches in the context of trust in their team. In order to foster an atmosphere of trust as a necessary condition for transformation (Eisen, 2001), the team must protect the vulnerability of novice faculty members who have confidence in their discipline but not necessarily in pedagogy (Campbell et al. 2009). To do this, the design team must be cognizant that they are interacting with a faculty member who may be experiencing a challenging role reversal, and "view the work that they do from an adult learning prospective" (McQuiggan, 2012, p32).

4. Workload and Time Management: Participants in this study thought they understood the time and preparation required for on-campus course delivery, yet were challenged by the work required to complete all development prior to the start of term. The additional complexity of faculty members' need to balance other commitments added further stress to the process. To address these challenges, more consideration should be given to workload and time requirements, both in scheduling development projects and in onboarding faculty members.

\section{Conclusion}

This study examines the pedagogical journey of three new online instructors participating in an intensive online course development process, while supported by a multidisciplinary team. Findings revealed that faculty reflected positively on the overall development process and intend to incorporate elements into future course design, suggesting that the model in its current state provides a solid foundation for online course development and faculty support. The experiences reported by the faculty align with Cranton's model of Transformative Learning (2002) and suggest that faculty experienced an element of transformative learning during the course development process. The analysis also revealed opportunities where enhancements to the model would further empower faculty to gain confidence in online design. Continuing to engage with faculty moving forward would contribute to an understanding of how the model of support used in this study could be further developed.

\section{References}

Allen, J. E. (2017). Transformative learning theory as a basis for identifying barriers to faculty confidence in online instruction.

Barker, A. (2003). Faculty development for teaching online: Educational and technological issues. Journal of Continuing Education in Nursing, 34(6), 273-278.

Bower, B. L. (2001). Distance education: Facing the faculty challenge. Online Journal of Distance Learning Administration, 4(2), 1-6. 
Brown, D. M. (2016). Training online faculty: Best practices versus reality - A mixed method case study. Available from ProQuest Dissertations \& Theses Global (1847568149). Retrieved from https://search.proquest.com/docview/184 7568149? accountid $=6180$

Campbell, K., Schwier, R. A., \& Kenny, R. F. (2009). The critical, relational practice of instructional design in higher education: An emerging model of change agency. Educational Technology Research and Development, 57(5), 645-663.

Caplan, D. (2004). The development of online courses. In T. Anderson \& F. Elloumi (Eds.), In theory and practice of online learning (pp. 175194). Edmonton, AB: Athabasca University Press.

Covington, D., Petherbridge, D., \& Warren, S. E. (2005). Best practices: A triangulated support approach in transitioning faculty to online teaching. Online Journal of Distance Learning Administration, 8(1), 3-14.

Cranton, P. (2002). Teaching for transformation. New Directions for Adult and Continuing Education, 93(2), 63-67.

Cranton, P., \& Taylor, E. (2012). Transformative learning theory: Seeking a more unified theory. In E. Taylor \& P. Cranton (Eds.), The handbook of transformative learning: Theory, research and practice (pp. 3-20). San Francisco: JosseyBass.

Cranton, P. (2013). Transformative learning. In P. Mayo (Ed.), Learning with adults: International issues in adult education. Rotterdam: Sense Publishers. Retrieved from https://doi.org/10.1007/978-94-6209-3355_20

Donovan, T., Bates, T., Seaman, J., Mayer, D., Martel, E., Paul, R., Desbiens, B., Forssman, V., \& Poulin, R. (2018). Tracking online and distance education in Canadian universities and colleges: 2018 Canadian national survey of online and distance education. Retrieved from

https://onlinelearningsurveycanada.ca/publ ications-2018/
Eisen, M. J. (2001). Peer-based professional development viewed through the lens of transformative learning. Holistic Nursing Practice, 16(1), 30-42.

Frenk, J., Chen, L., Bhutta, Z. A., Cohen, J., Crisp, N., Evans, T., \& Kistnasamy, B. (2010). Health professionals for a new century: Transforming education to strengthen health systems in an interdependent world. The Lancet, 376, 1923-1958.

Giovanni, D. L., \& Tesone, D. V. (2003). What academic administrators should know to attract senior level faculty members to online learning environments. Online Journal of Distance Learning Administration, 6(1).

Grover, K. S., Walters, S., \& Turner, R. C. (2016). Exploring faculty preferences for mode of delivery for professional development initiatives. Online Journal of Distance Learning Administration, 19(1).

Halupa, C. (2019). Differentiation of Roles: Instructional Designers and Faculty in the Creation of Online Courses. International Journal of Higher Education, 8(1), 55-68.

Kebritchi, M., Lipschuetz, A., \& Santiague, L. (2017). Issues and challenges for teaching successful online courses in higher education: A literature review. Journal of Educational Technology Systems, 46(1), 4-29. doi:10.1177/0047239516661713

Keen, C. H., \& Woods, R. (2016). Creating activating events for transformative learning in a prison classroom. Journal of Transformative Education, 14(1), 15-33.

King, K. (2004). Both sides now: Examining transformative learning and professional development of educators. Innovative Higher Education, 29(2), 155-174. Retrieved from https://link.springer.com/article/10.1023/ B:IHIE.0000048796.60390.5f

Kraglund-Gauthier, W., Chareka, O., Orr, A., \& Foran, A. (2010). Teacher education in online classrooms: An inquiry into instructors' lived experiences. Canadian Journal for the Scholarship of Teaching and 
Learning, 1(2), 1-11. doi:10.5206/cjsotlrcacea.2010.2.4

Kreber, C. (2004). An analysis of two models of reflection and their implications for educational development. International Journal for Academic Development, 9(1), 29-49.

McQuiggan, C. A. (2012). Faculty development for online teaching as a catalyst for change. Journal of Asynchronous Learning Networks, 16(2), 27-61.

Mezirow, J. (1996). Contemporary paradigms of learning. Adult Education Quarterly, 46(3), 158-172.

https://doi.org/10.1177/074171369604600 303

Mezirow, J. (1997). Transformative learning: Theory to practice. New Directions for Adult and Continuing Education, no. 74, 5-12.

Noble, H., \& Smith, J. (2015). Issues of validity and reliability in qualitative research. EvidenceBased Nursing, 18(2), 34-35. doi:10.1136/eb2015-102054

Newman, M. (2012). Calling transformative learning into question: Some mutinous thoughts. Adult Education Quarterly, 62, 399-411.

Stake, R. (2000). Case studies. In N. Denzin \& Y. Lincoln (Eds.), Handbook of qualitative research (pp. 435-454). Thousand Oaks, CA: Sage.

Stake, R. (2010). Qualitative research: Studying how things work. New York, NY: Guildford Press.

Riches, C., \& Benson, F. (2011, November). Being the 'other': Epiphanies from international field experiences and evidence for practice. Paper presented at the Joint Conference of the Applied Linguistics Association of Australia and the Applied Linguistics Association of New Zealand, Canberra, Australia.
Wilson, G., \& Stacey, E. (2003). Online interaction impacts on learning: Teaching the teachers to teach online. In G. Crisp, D. Thiele, I. Scholten, S. Barker, \& J. Baron (Eds.), Interact, integrate, impact: Proceedings of the 20th Annual Conference of the Australasian Society for Computers in Learning in Tertiary Education (pp. 541-551).

\section{Biographies}

Bev King is Assistant Dean, Teaching and Learning, in the Faculty of Arts and Science at Queen's University and leads its elearning unit, Arts and Science Online.

Keren Akiva, Wanda Beyer, Christina Dinsmore and Antoinette Thornton are Instructional Designers/Curriculum Developers in Arts and Science Online.

CJ Dalton was the research assistant on this project. 